\title{
Hexa-CAF Regimen
}

National Cancer Institute

\section{Source}

National Cancer Institute. Hexa-CAFRegimen. NCI Thesaurus. Code C9598.

A chemotherapy regimen consisting of hexamethylmelamine, cyclophosphamide,

methotrexate, and fluorouracil that may be used in the treatment of ovarian cancer. 